\title{
UCB-NE-107 User's Manual
}

William W.-L. Lee

Earth Sciences Division Lawrence Berkeley Laboratory 1 Cyelotron Road Berkeley, CA 94720

March 1989

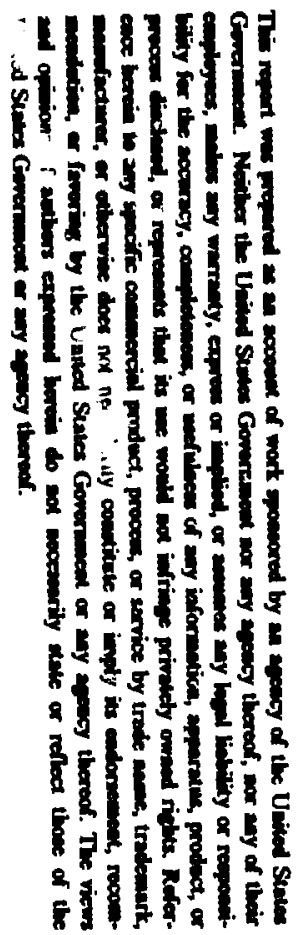




\section{ITIRODUCTON}

The purpose of this manual is to provide users of UCB-NE-107 with the information necesary to use UCBNE-107 effectively.

\section{DESCRTPION OF THE CODE}

UCB-NE-107 is a computer code for calculating the fractional release rate ${ }^{2}$ of readily soluble radionuclides that are released from nuclear waste emplaced in water-aturated porous media. Wate placed in such environments will gradually dimolve. For many apecies such a sctinides and rare earthe, the procen of dimolution in governed by the exterior flow field, and the chemical reacticn rate or leaching rate. ${ }^{3}$ However, for readily soluble apecies auch $2{ }^{134} \mathrm{Cs},{ }^{137} \mathrm{Cs}$ and ${ }^{129} 1$, it he been oberved that their dimolution rates are rapid. UCB-NE-107 is a code for salculating the release rate at the wate/rock interface, to check compliance with the U.S. Nuclear Regulatory Comminion's (USNRC) subsyatem performance objective. It is an implementation of the andytic solution given below.

\section{TH:ORT}

Small fraction of the more soluble apecies, e.s., cenium and iodine, are releaned from the $\mathrm{UO}_{2}$ matrix durins ractor operation and are present in $\mathrm{UO}_{2}$ grain bounderiea and pores and in fuel-claddins gapa. Upoe contact with ground water that penetrates friled conteiners and fills voido in wate packeges, these

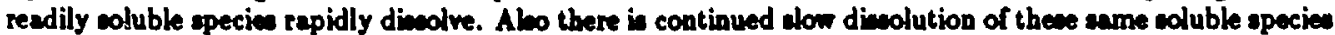
a the mate matrix dimolves in the void water. We sosume that the eurroundins poroun rock in in direct contact with the well-mixed void liquid (Fizure 1), that contains initially a epecified quantity of thene readily soluble species. The specie migrate into the porow material under a concentration gradient. Anuming that advective transport in the near-fold is anall compared with difiuive transport, the epace-time-dependent concentration $N(x, t)$ in pore water in given by

$$
K \frac{\partial N(x, t)}{\partial t}=D, \frac{\partial^{2} N(x, t)}{\partial x^{2}}-\lambda K N(x, t), \quad x>a, \quad t>0
$$

where $D_{f}$ in the specie diffusion conficient $\left[\mathrm{L}^{2} / \mathrm{T}\right]$ in the porous rock, and $K$ in the opecies retardation conficient.

The initial and boundary condition are

$$
\begin{array}{llrl}
N(x, 0) & =0, & & >a \\
N(\alpha, t) & =N(t), & t \geq 0 \\
N(\infty, t)=0, & t \geq 0
\end{array}
$$

where $\alpha$ is the thicknew of the "gep" filled with void water. Here $N(t)$ is the time-dependent well-mixed concentration of the soluble specien in the water in the void. To solve for $N(t)$, the man balance in the void in

$$
V \frac{d N(t)}{d}=\dot{m}_{f}(t)-\dot{m}(t)-\lambda V N(t), \quad t>0
$$

where $\dot{m}_{f}(t)$ is the rate of diesolution of the specien from the wate matrix into the void volume $V$, and $\dot{m}(t)$ is the rate of apecien migration into the rock. To wolve (5), we use the initial condition

$$
N(0)=N^{\bullet}
$$

where $N^{*}$ is the initial concentration of the species in the void water.

Chambret has obtained the solution to (1) through (6) reaulting in the concentration of soluble species in the void $a$

$$
N(t)=N^{\bullet} e^{-\lambda t} F\left(\beta^{2} t\right)+\frac{1}{V} \int_{0}^{t} \dot{m}_{f}(t-\tau) e^{-\lambda \tau} F\left(\beta^{2} \tau\right) d \tau, \quad t>0
$$


where

$$
F\left(\beta^{2} t\right) \equiv e^{\rho^{2}} \operatorname{erfc} \sqrt{\beta^{2} t}
$$

and

$$
\theta \equiv \sqrt{D, K \epsilon^{2} / \alpha^{2}}
$$

The mam flux of the epecien into the rock is

$$
\dot{m}(t)=-S D_{f} \epsilon \frac{\partial N(\alpha, t)}{\partial x}, \quad t>0
$$

where $S$ is the murface aros of the interface between the roid apace and the rock $(S \equiv V / \alpha)$. Uning $(6)$ the colution to (7) in

$$
\dot{m}(t)=N^{*} \beta V_{\cdot}-\lambda t\left\{\frac{1}{\sqrt{\pi t}}-\beta F\left(\beta^{2} t\right)\right\}+\beta \int_{0}^{t} n_{j}\left(t-\because \cdot \lambda r\left\{\frac{i}{\sqrt{\pi r}}-\beta \mathrm{F}\left(\beta^{2} r\right)\right\} d r, \quad t>0\right.
$$

from which the fractional releen rate can be calculated.

\section{Aroping:}

UCB-NE-107 in an implematation of (9). Dq. (9) shom that the tux rate is the sum of the fux from the specien rebaed inctentancounly in the zap, and the epecien relesend congruently from the wente matrix.

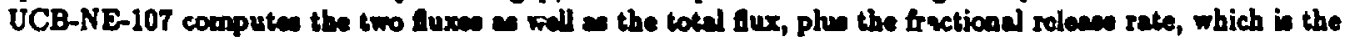
total flux divided by the initial of 1000-year inmetory. UCB-NE-107 aloo computen the concentration in the sap due to the initially releand alug, and that from congruent relowe, all as their oum.

The evaluation of

$$
F\left(\beta^{2} t\right)=\rho^{\alpha} \operatorname{arfc} \sqrt{\beta^{2} t}
$$

is by an adaptation of the retional approximation of the error function."

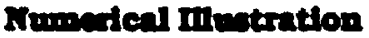

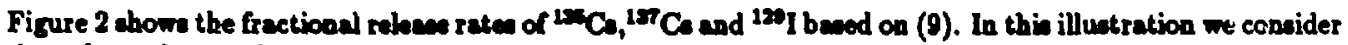
the relese from a bers wate form exponed to ground water ebortly ater emplecement, conervatively

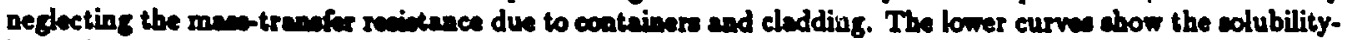
limiled diecolution rate froen the wente matrix, aneming congruest divolution and a uranium colubility of $10^{-3} \mathrm{~g} / \mathrm{m}^{3}$. A concerntively high diffuion concinat of $0.12 \mathrm{~m}^{2} / \mathrm{a}$ in wout throughout the anelyin, and a

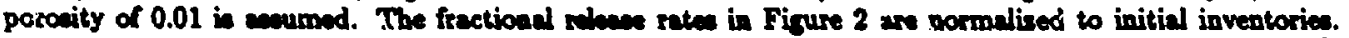
At $t=0$, one percent of these epecin in annend to dimolve into the water-filled void epece of $0.45 \mathrm{~m}^{2}$.

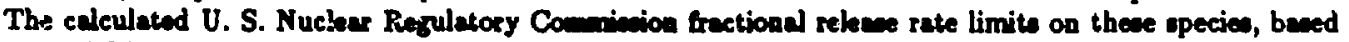
on initial inventorien, are

$$
\begin{aligned}
{ }^{13} \mathrm{Cs} & =4.5 \times 10^{-1} \text { per year } \\
{ }^{197} \mathrm{C} s & =1.8 \times 10^{-10} \text { per your } \\
{ }^{120} \mathrm{I} & =5.4 \times 10^{-4} \text { per year }
\end{aligned}
$$

With these parameters, the early contribution from gap inventory is more than $10^{7}$-fold greater then the contribution from the wate matrix. For eath timen, the frectiond releave ratee of ${ }^{135} \mathrm{Co}$ and ${ }^{137} \mathrm{C}$ s are almost equal, but the ${ }^{157} \mathrm{Co}$ releace rate docromen rapidly because of radionctive decay, wherean the releane rate of $3 \times 10^{6}$-year ${ }^{136} \mathrm{C}$ is characteriatic of a atable apecies. Becaure of the amumed negligible arption of iodine in the rock, the early fractional releane rete of $1.7 \times 10^{7}$-year ${ }^{139} \mathrm{I}$ is lower than the ratee of atrongly corbing cenium, but the leas rapid early depletion of iodine in the void water result in a greater fractional releace rate of iodine after about 20 years. 
The fractional releace rate of ${ }^{137} \mathrm{C}$ exceeds the USNRC releace rate limit for several hundred years. The preance of metallic containers, and the time-dintributed nature of container failure will likely belp meet the requirement.

\section{INPUT}

The input consiats of 4 lines. UCB-NE-107 looks for a file called UCB107.dat as the input.

Firat line (free format)

RSP; equivalent wate-aphere radius (m)

DF; difturion conficient $\left(\mathrm{m}^{2} / \mathrm{a}\right)$

EPS; poronity of rock (-)

VOL; volume of $\operatorname{cep}\left(\mathrm{m}^{3}\right)$

WID; sap width (m)

Second line (free format)

AK; retardation coefincient of apecies (-)

CONI; initial inventory of apecies in mente solid (s)

SNGAP; initial concentration of apecian in $8 \mathrm{ap}\left(\mathrm{g} / \mathrm{m}^{3}\right)$

RAMBDA; decay content of epecies (1/a)

Third line (free format)

ZK; retardation coeficient of the rete matrix (-)

CONA; initial inventory of matrix in the wate (s)

CS; colubility of dimolution controllet $\left(\mathrm{e} / \mathrm{m}^{3}\right)$

Fourth line (free format)

NOPTION; option for output to FORO09

TJUG; which initial inventory to uev

An example input file follows.

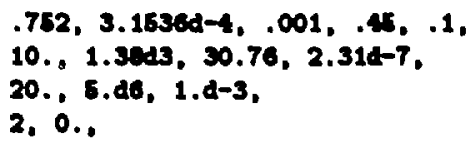

\section{Ouxrox}

There are two output atream. The firat in a tabular output, currently directed to the ecreen. The mecond is a stream of output data, for use by a X-Y plotter or plotting program such a TELL-A-GRAF.

The tabular output is currently directed to the erreen by a

WRITE $(*, x \times x)$

statement. In a DEC/VAX computer this outyat can be directed to a file by a command auch as

ASSIGN SYS\&OUTPUT filename .

Please note that the tabular output is 80 colunes wide. The output first prints out mont of the input date.

It aloo prints out the calculated leach time for the wate. Then in a table of 8 columna it lints

Time (a)

Concentration in the Gap Due to Instantaneous Release $\left(\mathrm{g} / \mathrm{m}^{3}\right)$

Concentration in the Gap Due to Congrwent Release from the Matrix $\left(\mathrm{g} / \mathrm{m}^{3}\right)$

Total Concentration in the Gap $\left(\mathrm{g} / \mathrm{m}^{3}\right)$

Mase Flux Rate at Waste/Rock Interface Due to Inatantaneous Release $(\mathrm{g} / \mathrm{a})$

Mas Flux Rate at Waste/Rock Interface Due to Congruent Release (g/a)

Total Mase Flux Rate at Waste/Rock Interface (g/a)

Fractional Release Rate at: Waste/Rock Interface (1/a) 
The file FOR009.dat contains two columns of numbers. The first column is always the time in years. The second column depends on the value of NOPTION. If NOPTION=1, the second column contains the total fractional release rate $(1 / \mathrm{a})$. If NOPTION=2, the second column contains the fractional release rate (FRR) considering only the contribution of the instantaneously released species. If NOPTION=3, the second column contains the fractional release rate (FRR) considering the contribution from congruent dissolution from the waste matrix only. If NOPTION-4, the second column contains the total mass flux (g/a). If NOPTION=1, 2, 3 the fractional release $y$ : release rate is based on the initial inventory and if $T J U G=1000$, the fractional release rate is based on the thousand-year inventory.

\section{RESOURCE REQURENDWNS}

UCB-NE-107 is written in FORTRAN and does not call any outside libraries. It operates on DEC/VAX and DEC/UNIX machines.

\section{VERMMCATION \& BENCEMARIING}

UCB-NE-107 in an implementation of (9). It was verified through hand calculations. The correctneas of UCB-NE-107 was alwo checked this way. Eq. (9) was given to several workers and they were anked to write computer program independently. The outputu of the various programe are then compared or benchmarked. They gave identical reaults. The current UCB-NE-107 is in fact a combination of the best features of several programs.

\section{RETERENCES}

1. C. L. Kim, P. L. Chambré and T. H. Pigford, "Mane-Tranafer Limited Release of a Soluble Waste Speciea," Trans. Am. Nuc. Soc., 52, 80, 1986.

2. U. S. Nuclear Regulatory Comminion, Diepoeal of High-Level Radionctive Wastes in Geologic Repositorien, 10 Cade of Pederal Regulations 60.113(a)(1)(ii)(B).

3. P. L. Chambré, C. H. Kang, W. W.-L. Lee and T. H. Pigford, "The Role of Chemical Reaction in Wate-Form Performance, ${ }^{\infty}$ in M. J. Apted and R. E. Weaterman (eds.), Scientific Basis for Nuclear Waste Management XI, 285, Pittsburgh, Materials Research Society, 1988

4. P. L. Chambré, to be published.

5. K. H. Hakell and R. E. Jones, 1978. Brief Instructions for Using the Sendia Mathematical Subroutine Librery (Version 7.2), SAND77-1441. 


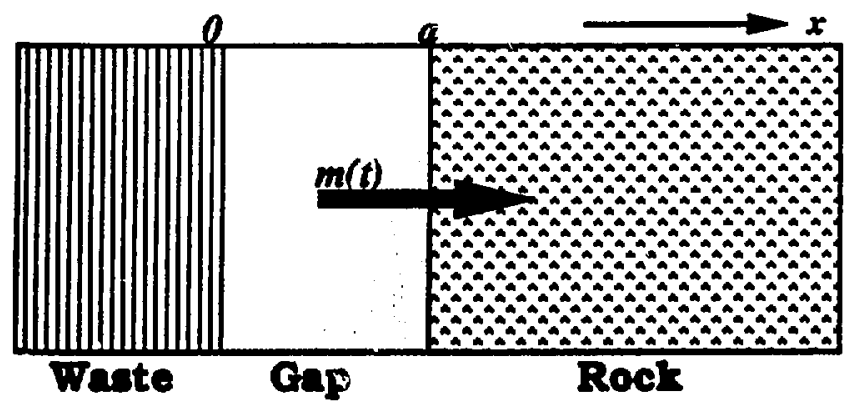

Figure 1. Release of Soluble Species 
Figure 2. An Example of FOR009 Output Plotted Using TELL-A-GRAF. Fractional Pelease Rates of Some Soluble Snecies.

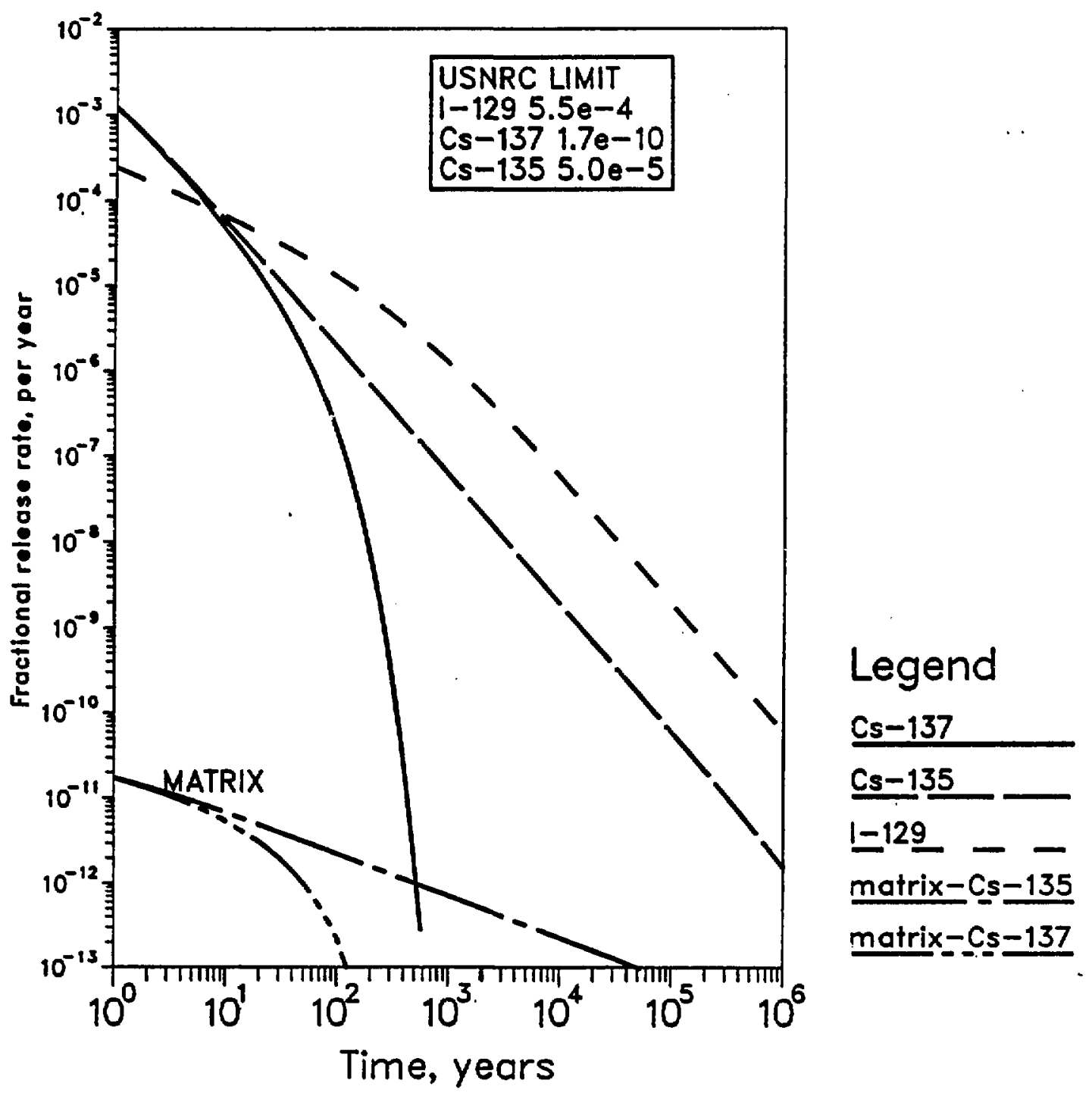




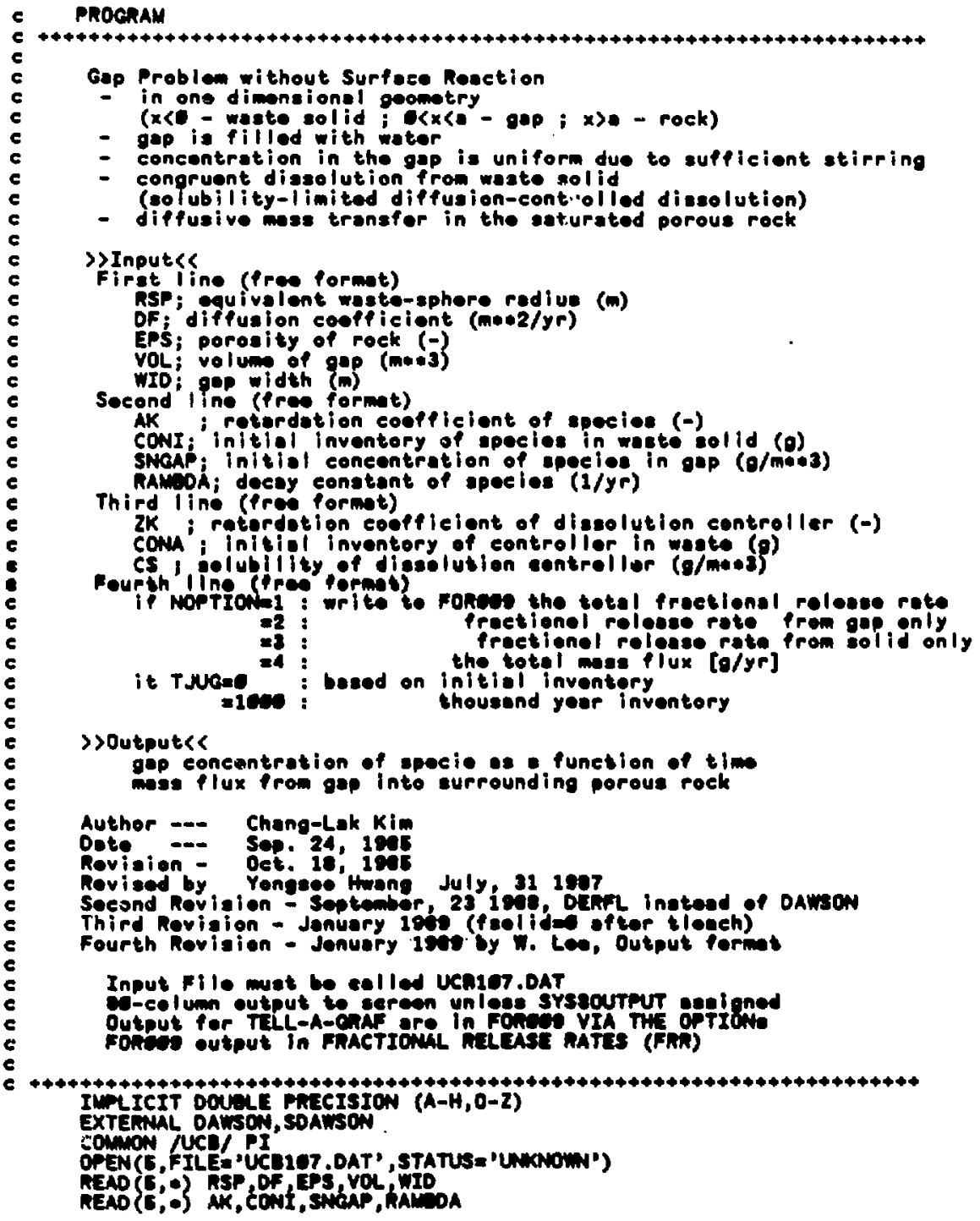




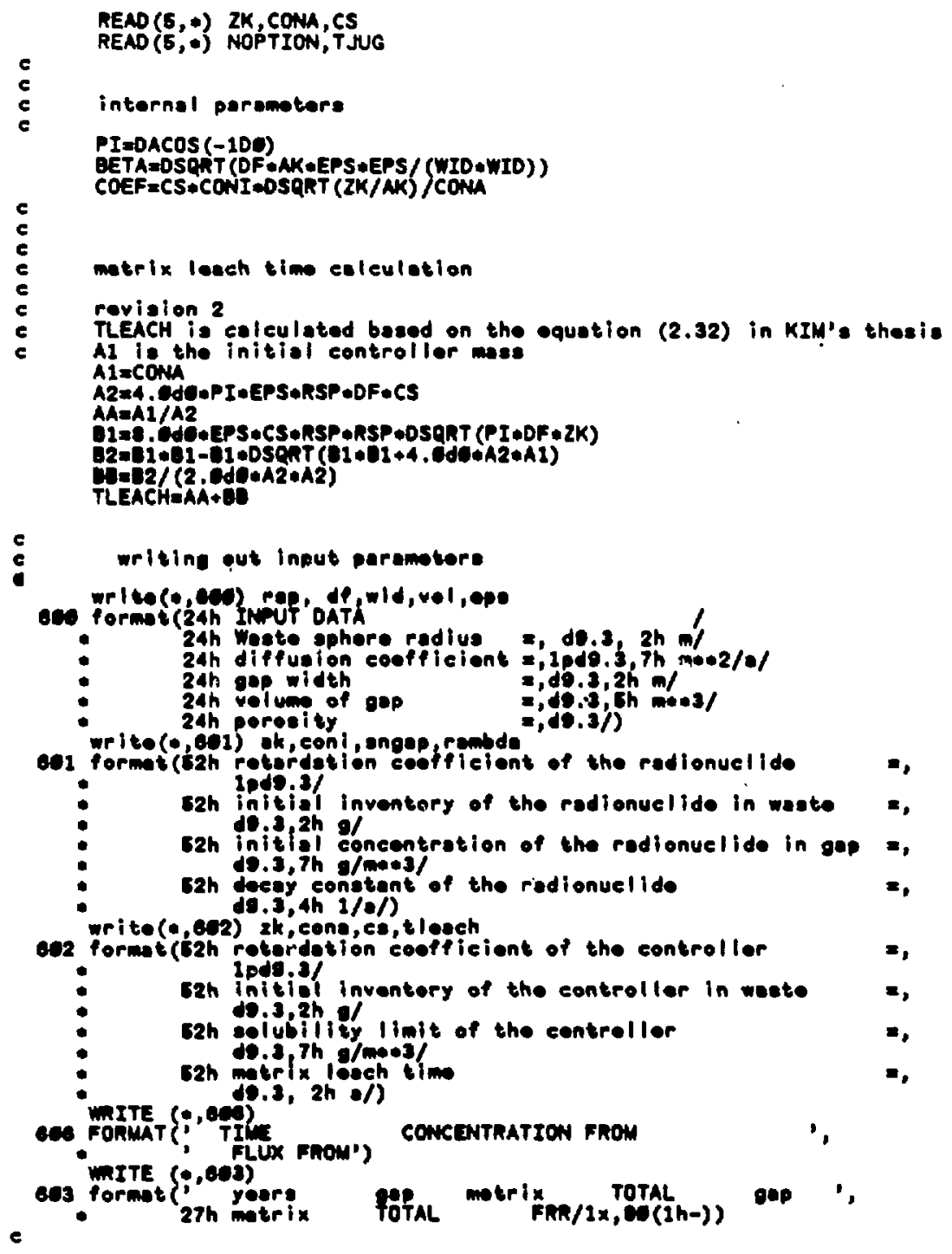




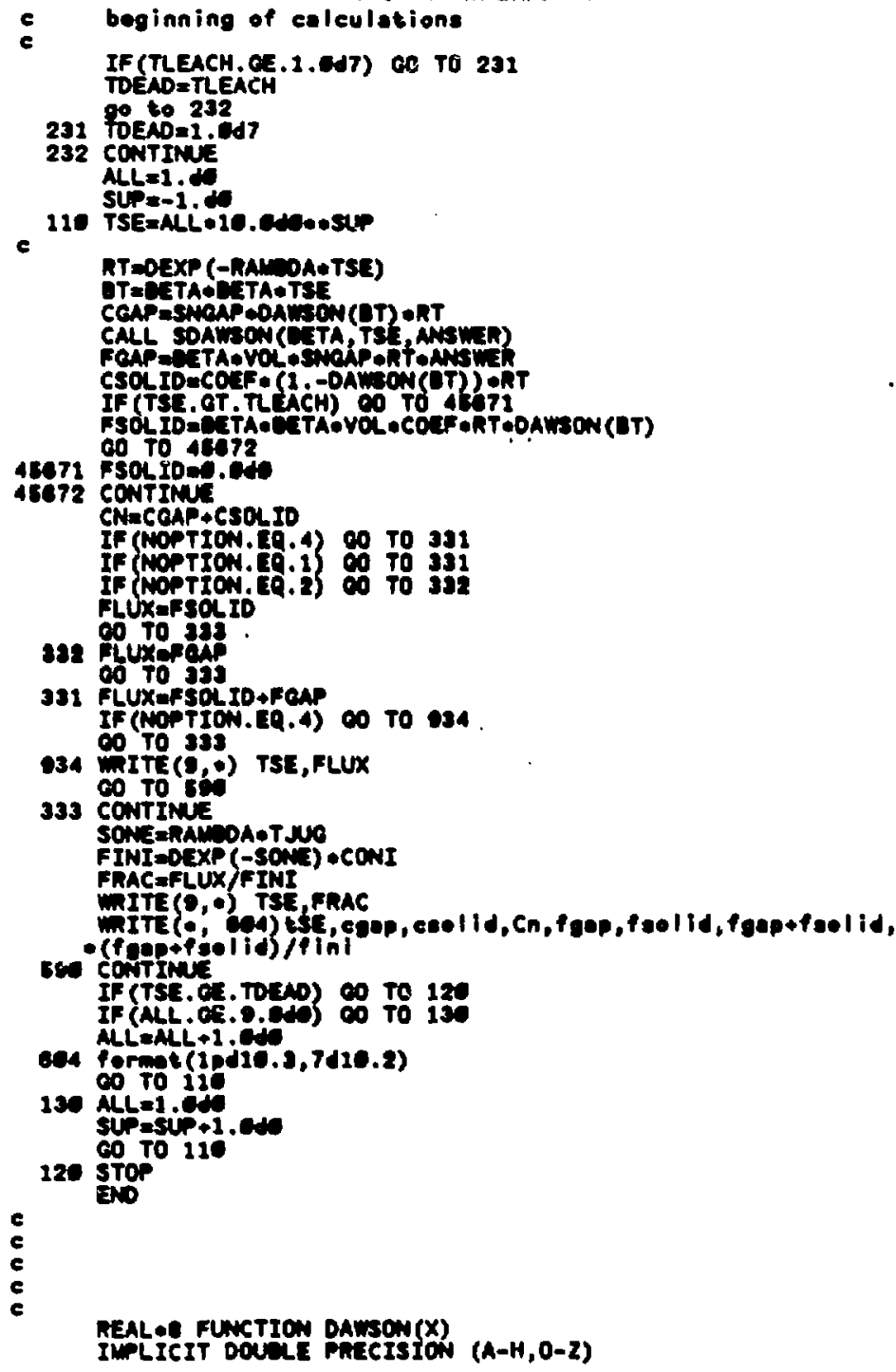

Cen Pormet (ipd10.9,7d10.2)

co ro 120

130 ALL=1.019

SYP $=54+1.04$

$12.3 \mathrm{TrO}$

co TO 110

ENo

5
$c$
$c$

REAL *A FUnCTION DAmSON(x)

IMPLICIT DOULE PAECISION (A-H, 0-Z) 
ExTERNAL EAFL

$X \times 2=D S C H T(x)$

DAWSOHLEnFL $(X X 2)$

RETUNW

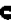

END

SUENOUTIM: SOAHSON (BETA, TSE, ANSWER)

IWLICIT DOULE PRECISION $(A-H, 0-Z)$

Extefrul Enfl

Cominow JUCD/PI

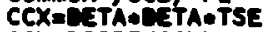

cex $\Rightarrow$ sont (cex)

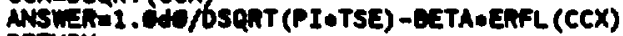

RETUNH

END

c

FUNTION GNL(XS)

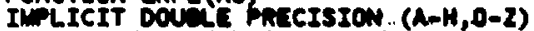

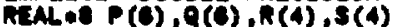

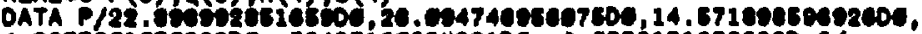

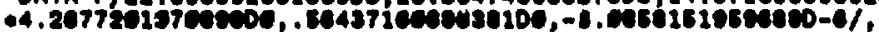

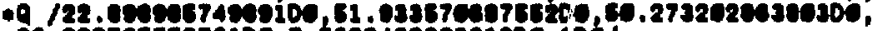

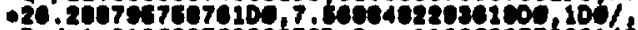

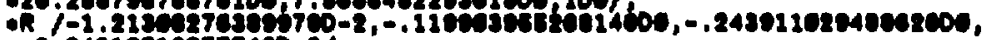

-3.2431 19277740-2/.

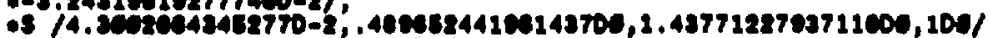

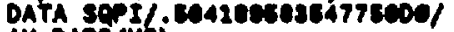

Axph (x)

IP (Ax.8T.4.e) os ro 10

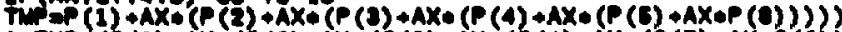

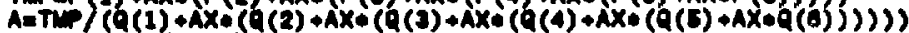

ERFL $=0$ SICN $(A, x B)$

co to 11

10 ConTIN

$x 2=1 . / A x / A x$

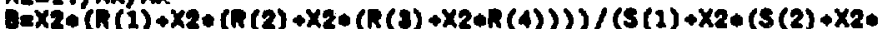

$(5(3)+x+1(4)))$

$A=(\sec I+b) / A x$

11 contrus

RETUnN

EDD 


$\begin{array}{ll}\text { Waste sphere radius } & =0.752 \mathrm{D}+00 \mathrm{~m} \\ \text { diffusion coefficient } & -3.154 \mathrm{D}-04 \mathrm{~m}^{\star \star 2} / \mathrm{a} \\ \text { gap width } & =1.000 \mathrm{D}-01 \mathrm{~m} \\ \text { volume of gap } & =4.500 \mathrm{D}-01 \mathrm{~m}^{\star \star 3} \\ \text { porosity } & -1.000 \mathrm{D}-03\end{array}$

retardation coefficient of the radionuclide initial inventory. of the radionuclide in waste initial concentration of the radionuclide in gap decay constant of the radionuclide

retardation coefficient of the controller initial inventory of the controlier in waste solubility Iimit of the controller matrix leach time

\author{
$=1.000 \mathrm{D}+01$ \\ $=1.380 \mathrm{D}+03 \mathrm{~g}$ \\ $=3.076 \mathrm{D}+01 \mathrm{~g} / \mathrm{m} * * 3$ \\ $=2.310 \mathrm{D}-07 \mathrm{1} / \mathrm{a}$ \\ $-2.000 D+01$ \\ $-5.000 \mathrm{D}+06$ \\ $=1.000 \mathrm{D}-03 \mathrm{~g} / \mathrm{m} * \star 3$ \\ $=1.678 \mathrm{D}+15 \mathrm{a}$
}

\begin{tabular}{|c|c|c|c|c|c|c|c|}
\hline $\begin{array}{l}\text { TIME } \\
\text { years }\end{array}$ & $\begin{array}{l}\text { CONC } \\
\text { gap }\end{array}$ & $\begin{array}{l}\text { ATRATION } \\
\text { matrix }\end{array}$ & TOMAI & gap & $\begin{array}{l}\text { SUX FROH } \\
\text { itrix }\end{array}$ & TOTAI & FRR \\
\hline $\begin{array}{l}.000 D-01 \\
.000 D-01 \\
.000 D-01 \\
.000 D-01 \\
.000 D-01 \\
.000 D-01 \\
.000 D-01 \\
.000 D-01 \\
.000 D-01 \\
.000 D+00 \\
.000 D+00 \\
.000 D+00 \\
.000 D+00 \\
.000 D+00 \\
.000 D+00 \\
.000 D+0.0 \\
.000 D+00 \\
.000 D+00 \\
.000 D+01 \\
.000 D+01 \\
.000 D+01 \\
.000 D+01 \\
.000 D+01 \\
.000 D+01 \\
.000 D+01 \\
000 D+01 \\
.000 D+01 \\
.000 D+02 \\
.000 D+02 \\
.000 D+02 \\
.000 D+02 \\
.000 D+02 \\
.000 D+02 \\
.000 D+02 \\
000 D+02 \\
.000 D+02 \\
000 D+03 \\
.000 D+03\end{array}$ & $\begin{array}{l}3.08 D+01 \\
3.08 D+01 \\
3.07 D+01 \\
3.07 D+01 \\
3.07 D+01 \\
3.07 D+01 \\
3.07 D+01 \\
3.07 D+01 \\
3.07 D+01 \\
3.07 D+01 \\
3.07 D+01 \\
3.07 D+01 \\
3.07 D+01 \\
3.07 D+01 \\
3.07 D+01 \\
3.07 D+01 \\
3.07 D+01 \\
3.07 D+01 \\
3.07 D+01 \\
3.07 D+01 \\
3.07 D+01 \\
3.06 D+01 \\
3.06 D+01 \\
3.06 D+01 \\
3.06 D+01 \\
3.06 D+01 \\
3.06 D+01 \\
3.06 D+01 \\
3.05 D+01 \\
3.04 D+01 \\
3.04 D+01 \\
3.03 D+01 \\
3.03 D+01 \\
3.02 D+01 \\
3.02 D+01 \\
3.02 D+01 \\
3.01 D+01 \\
2.99 D+01\end{array}$ & $\begin{array}{l}7.81 D-11 \\
1.10 D-10 \\
1.35 D-10 \\
1.56 D-10 \\
1.75 D-10 \\
1.91 D-10 \\
2.07 D-10 \\
2.21 D-10 \\
2.34 D-10 \\
2.47 D-10 \\
3.49 D-10 \\
4.28 D-10 \\
4.94 D-10 \\
5.52 D-10 \\
6.05 D-10 \\
6.53 D-10 \\
6.98 D-10 \\
7.41 D-10 \\
7.81 D-10 \\
1.10 D-09 \\
1.35 D-09 \\
1.56 D-09 \\
1.74 D-09 \\
1.91 D-09 \\
2.06 D-09 \\
2.20 D-09 \\
2.34 D-09 \\
2.46 D-09 \\
3.47 D-09 \\
4.25 D-09 \\
4.90 D-09 \\
5.47 D-09 \\
5.98 D-09 \\
6.46 D-09 \\
6.90 D-09 \\
7.31 D-09 \\
7.70 D-09 \\
1.08 D-08\end{array}$ & $\begin{array}{l}3.08 D+01 \\
3.08 D+01 \\
3.07 D+01 \\
3.07 D+01 \\
3.07 D+01 \\
3.07 D+01 \\
3.07 D+01 \\
3.07 D+01 \\
3.07 D+01 \\
3.07 D+01 \\
3.07 D+01 \\
3.07 D+01 \\
3.07 D+01 \\
3.07 D+01 \\
3.07 D+01 \\
3.07 D+01 \\
3.07 D+01 \\
3.07 D+01 \\
3.07 D+01 \\
3.07 D+01 \\
3.07 D+01 \\
3.06 D+01 \\
3.06 D+01 \\
3.06 D+01 \\
3.06 D+01 \\
3.06 D+01 \\
3.06 D+01 \\
3.06 D+01 \\
3.05 D+01 \\
3.04 D+01 \\
3.04 D+01 \\
3.03 D+01 \\
3.03 D+01 \\
3.02 D+01 \\
3.02 D+01 \\
3.02 D+01 \\
3.01 D+01 \\
2.99 D+01\end{array}$ & $\begin{array}{l}1.39 D-02 \\
9.80 D-03 \\
8.00 D-03 \\
6.93 D-03 \\
6.20 D-03 \\
5.66 D-03 \\
5.24 D-03 \\
4.90 D-03 \\
4.62 D-03 \\
4.38 D-03 \\
3.10 D-03 \\
2.53 D-03 \\
2.19 D-03 \\
1.96 D-03 \\
1.79 D-03 \\
1.65 D-03 \\
1.55 D-03 \\
1.46 D-03 \\
1.38 D-03 \\
9.76 D-04 \\
7.96 D-04 \\
6.89 D-04 \\
6.16 D-04 \\
5.62 D-04 \\
5.6 D-04 \\
4.86 D-04 \\
4.58 D-04 \\
4.34 D-04 \\
3.06 D-04 \\
2.49 D-04 \\
2.15 D-04 \\
1.92 D-04 \\
1.75 D-04 \\
1.61 D-04 \\
1.51 D-04 \\
1.42 D-04 \\
1.34 D-04 \\
9.38 D-05\end{array}$ & $\begin{array}{l}5.54 D-14 \\
5.54 D-14 \\
5.54 D-14 \\
5.54 D-14 \\
5.54 D-14 \\
5.54 D-14 \\
5.54 D-14 \\
5.54 D-14 \\
5.54 D-14 \\
5.54 D-14 \\
5.53 D-14 \\
5.53 D-14 \\
5.53 D-14 \\
5.53 D-14 \\
5.53 D-14 \\
5.53 D-14 \\
5.53 D-14 \\
5.53 D-14 \\
5.53 D-14 \\
5.52 D-14 \\
5.52 D-14 \\
5.52 D-14 \\
5.51 D-14 \\
5.51 D-14 \\
5.51 D-14 \\
5.51 D-14 \\
5.51 D-14 \\
5.50 D-14 \\
5.49 D-14 \\
5.48 D-14 \\
5.47 D-14 \\
5.46 D-14 \\
5.45 D-14 \\
5.45 D-14 \\
5.44 D-14 \\
5.43 D-14 \\
5.43 D-14 \\
5.38 D-14\end{array}$ & $\begin{array}{l}1.39 D-02 \\
9.80 D-03 \\
6.00 D-03 \\
6.93 D-03 \\
6.20 D-03 \\
5.66 D-03 \\
5.24 D-03 \\
4.90 D-03 \\
4.62 D-03 \\
4.38 D-03 \\
3.10 D-03 \\
2.53 D-03 \\
2.19 D-03 \\
1.96 D-03 \\
1.79 D-03 \\
1.65 D-03 \\
1.55 D-03 \\
1.46 D-03 \\
1.38 D-03 \\
9.76 D-04 \\
7.96 D-04 \\
6.89 D-04 \\
6.16 D-04 \\
5.62 D-04 \\
5.20 D-04 \\
4.86 D-04 \\
4.58 D-04 \\
4.34 D-04 \\
3.06 D-04 \\
2.49 D-04 \\
2.15 D-04 \\
1.92 D-04 \\
1.75 D-04 \\
1.61 D-04 \\
1.51 D-04 \\
1.42 D-04 \\
1.34 D-04 \\
9.38 D-05\end{array}$ & $\begin{array}{l}1.00 D-05 \\
7.10 D-06 \\
5.80 D-06 \\
5.02 D-06 \\
4.49 D-06 \\
4.10 D-06 \\
3.80 D-06 \\
3.55 D-06 \\
3.35 D-06 \\
3.17 D-06 \\
2.24 D-06 \\
1.83 D-06 \\
1.59 D-06 \\
1.42 D-06 \\
1.29 D-06 \\
1.20 D-06 \\
1.12 D-06 \\
1.06 D-06 \\
1.00 D-06 \\
7.07 D-07 \\
5.77 D-07 \\
4.99 D-07 \\
4.46 D-07 \\
4.07 D-07 \\
3.77 D-07 \\
3.52 D-07 \\
3.32 D-07 \\
3.15 D-07 \\
2.22 D-07 \\
1.80 D-07 \\
1.56 D-07 \\
1.39 D-07 \\
1.27 D-07 \\
1.17 D-07 \\
1.09 D-07 \\
1.03 D-07 \\
9.74 D-08 \\
6.80 D-08\end{array}$ \\
\hline
\end{tabular}


3. $0000+03$

4. $0.00 \mathrm{D}+03$

$5.000 D+03$

$6.000 \mathrm{D}+03$

$7.000 \mathrm{D}+03$

8.000D+03

9. $000 \mathrm{D}+03$

$1.000 \mathrm{D}+04$

$2.000 \mathrm{D}+04$

3. $000 D+04$

4.000D+0 4

$5.000 D+04$

$6.000 \mathrm{D}+04$

$7.000 \mathrm{D}+04$

$8.000 D+04$

9.000D+04

$1.000 D+05$

2.000D+05

$3.000 \mathrm{D}+05$

4. $000 D+05$

$5.000 D+05$

$6.000 \mathrm{D}+05$

$7.000 \mathrm{D}+05$

$8.000 D+05$

$9.000 D+05$

$1.000 D+06$

$2.000 D+06$

$3.000 D+06$

4. $000 \mathrm{D}+06$

$5.000 D+06$

$6.000 D+06$

$7.000 D+06$

8.000D+06

$9.000 \mathrm{D}+06$

$1.000 \mathrm{D}+07$

FORTRAN STOP
2.97D+01

$2.95 \mathrm{D}+01$

$2.94 D+01$

$2.93 \mathrm{D}+01$

2.91D+01

$2.90 D+01$

2.89D+01

$2.88 \mathrm{D}+01$

$2.81 D+01$

$2.75 \mathrm{D}+01$

$2.70 D+01$

$2.65 \mathrm{D}+01$

2.61D+01

$2.58 D+01$

2.55D+01

$2.52 D+01$

$2.49 D+01$

$2.26 D+01$

2.09D+01

$1.96 D+01$

$1.84 D+01$

1.74D+01

$1.65 \mathrm{D}+01$

$1.57 D+01$

$1.50 D+01$

1. $43 D+01$

$9.52 D+00$

$6.69 D+00$

$4.84 \mathrm{D}+00$

$3.55 \mathrm{D}+00$

2. $640+00$

$1.98 \mathrm{D}+00$

$1.490+00$

$1.13 D+00$

8. 6OD-01
1.32D-08

1.51D-08

$1.69 \mathrm{D}-08$

1.84D-08

1.98D-08

2.11D-08

2. 24D-08

2.35D-08

3. $25 \mathrm{D}-08$

3.91D-08

4. $45 \mathrm{D}-08$

4.91D-08

5.32D-08

5. $68 \mathrm{D}-08$

6.01D-08

6.31D-08

6.58D-08

8.59D-08

9.85D-08

$1.07 D-07$

1.14D-07

1.190-07

1.22D-07

1. 25D-07

1.27D-07

$1.28 D-07$

$1.25 D=07$

1.10D-07

9.35D-08

7.79D-08

6.41D-08

5.24D-08

4.26D-08

$3.45 \mathrm{D}-08$

2.78D-08
2. $97 \mathrm{D}+01$

2. $95 \mathrm{D}+01$

2. $94 \mathrm{D}+01$

2. $93 \mathrm{D}+01$

2.91D+01

2. $90 D+01$

2. $89 D+01$

$2.88 D+01$

$2.81 D+01$

$2.75 D+01$

$2.70 \mathrm{D}+01$

$2.65 D+01$

2. $61 D+01$

$2.58 D+01$

2.55D+01

2.52D+01

$2.49 D+01$

$2.26 \mathrm{D}+01$

$2.09 D+01$

$1.96 D+01$

$1.84 D+01$

1.74D+01

$1.65 \mathrm{D}+01$

$1.57 D+01$

$1.50 D+01$

$1.43 D+01$

$9.52 D+00$

6. $69 \mathrm{D}+00$

4. $84 D+00$

$3.55 D+00$

$2.64 D+00$

$1.98 D+00$

$1.49 D+00$

$1.13 D+00$

8. 60D-01
7.58D-05

6.51D-05

5.78D-05

5.24D-05

4.82D-05

4.48D-05

4.20D-05

3.97D-05

2.69D-05

2.12D-05

$1.79 \mathrm{D}-05$

1.56D-05

1. 39D-05

$1.26 \mathrm{D}-05$

$1.16 \mathrm{D}-05$

$1.07 D-05$

1.00D-05

6.16D-06

4.50D-06

3.54D-06

2.91D-06

2.46D-06

2.11D-06

1.85D-06

1.63D-06

1.45D-06

6.03D-07

3.16D-07

1.84D-07

1.14D-07

7.31D-08

4.83D-08

3.27D-08

2.24D-08

$1.56 \mathrm{D}-08$
5.35D-14

5. 32D-14

5.29D-14

5.27D-14

5.25D-14

5.23D-14

5.21D-14

5.19D-14

5.05D-14

4.95D-14

4. 86D-14

4.78D-14

4.71D-14

4.64D-14

4.59D-14

4.53D-14

$4.48 D-14$

4.07D-14

3.77D-14

3.53D-14

3.32D-14

$3.14 D-14$

2.98D-14

2.93D-14

2.70D-14

2.57D-14

1.71D-14

1.21D-14

8.71D-15

6.40D-15

4.75D-15

$3.56 \mathrm{D}-15$

2. $69 D-15$

2.03D-15

1.55D-15
7. 58D-05

6.51D-05

5.78D-05

5.24D-05

4. 82D-05

4.48D-05

4.20D-05

3.97D-05

2.69D-05

2.12D-05

1.79D-05

$1.56 \mathrm{D}-05$

1.39D-05

$1.26 D-05$

$1.16 \mathrm{D}-05$

$1.07 \mathrm{D}-05$

1. $00 D-05$

6.16D-06

4.50D-06

3.54D-06

2.91D-06

2.46D-06

2.11D-06

1.85D-06

1.63D-06

1. $45 \mathrm{D}-06$

6.03D-07

3.1 $16 D-07$

1.84D-07

1.14D-07

7. 31D-08

4. 83D-08

3. $27 \mathrm{D}-08$

2.24D-08

$1.56 \mathrm{D}-08$
5. 49D-08

4.72U-08

4.19D-08

3. $80 \mathrm{D}-08$

3. $49 \mathrm{D}-08$

3.25D-08

3.05D-08

2.87D-08

1.95D-08

1.54D-08

1.30D-08

$1.13 \mathrm{D}-08$

1.01D-08

9.17D-09

8.41D-09

7.79D-09

$7.26 \mathrm{D}-09$

4. 46D-09

3.26D-09

2.57D-09

2.11D-09

1. 78D-09

1. 53D-09

1.34D-09

1. 18D-09

1.05D-09

4. 37D-10

2. $29 \mathrm{D}-10$

1.33D-10

8.24D-11

5.30D-11

3.50D-11

2.37D-11

1.63D-11

1.13D-11 